\title{
Managing Sour Service in Oil Export and Onshore Pipelines: A Case Study
}

\author{
D. Ifezue - V. C. Nettikaden
}

Submitted: 12 February 2013/Published online: 23 March 2013

(C) The Author(s) 2013. This article is published with open access at Springerlink.com

\begin{abstract}
Thirteen extended $\mathrm{H}_{2} \mathrm{~S}$ excursions (19.64 mg/l maximum) above the Standard Operating Limit (SOL, $6.7 \mathrm{mg} / \mathrm{l})$, recorded for the export and onshore pipeline systems in January 2010, contravened the Pipelines Safety Regulations (PSR) 1996 and triggered an assessment to determine the safety of continued operation in a sour service condition. Sampling and monitoring results were assessed and the $\mathrm{pH}$ and $\mathrm{H}_{2} \mathrm{~S}$ partial pressures were found not to align with any of the ISO $15156 \mathrm{SCC}$ regions of environmental severity (0, 1, 2 and 3$)$. Both pipelines were, therefore, considered safe for continued operation as long as $\mathrm{pH}$ remained near-neutral above 6.5. Since $\mathrm{pH}$ was found to be the main driver for SSCC risk, $\mathrm{pH}$ analysis has been recommended for every pig receipt with $\mathrm{H}_{2} \mathrm{~S}$ and $\mathrm{CO}_{2}$ excursions being the main triggers. Also the high risk of HIC should be mitigated by maintaining $\mathrm{pH}$ at near-neutral levels. Very low $\mathrm{H}_{2} \mathrm{~S}$ levels have been achieved by pigging, biociding and scavenging and low corrosivities by adequate corrosion inhibition. Weld root hardness of the export pipeline $\left(295 \mathrm{HV}_{10}\right)$ is out of compliance with ISO 15156 hardness requirements for operating in the SCC region 0 (275 $\left.\mathrm{HV}_{10}\right)$. Risk-based inspection ( $\mathrm{RBI}$ ) reviews are recommended to determine inspection techniques and frequencies appropriate for all susceptible weldments.
\end{abstract}

Keywords Hardness - Corrosion failure analysis . Environmentally assisted cracking

D. Ifezue $(\bowtie)$

Wood Group Integrity Management, Staines TW18 1DT, UK e-mail: david.ifezue@wgim.com

V. C. Nettikaden

Perenco UK Ltd, Thames House, Norfolk, Great Yarmouth NR31 0DW, UK

\section{Introduction}

Background

The two pipelines covered by this paper are the export pipeline and the onshore receiving pipeline to a processing terminal. A central platform gathers oil from five other platforms. The $36^{\prime \prime}$ export pipeline then transport the co-mingled fluids from the central platform to a processing terminal. The export pipeline, terminating at the pig receiver, feeds the oil into the $36^{\prime \prime}$ onshore reception pipeline for processing at the terminal. Field architectures for the entire pipeline system and the export pipeline are illustrated schematically in Figs. 1 and 2. This asset has been in operation for 30 years.

This export pipeline is not intended for sour service and is considered to be potentially at risk from sulphide stress corrosion cracking (SSCC) especially at the welds and from hydrogen-induced cracking (HIC) at the parent plate. The onshore receiving pipeline was originally designed for sour service. However, several chemical injection valves were later welded-on at various locations on this pipeline. Since the welding was not qualified and no post-weld heat treatment (PWHT) of the heat affected zone (HAZ) was performed, the onshore pipeline is considered to be potentially at risk from SSCC at these weld locations.

These pipelines experienced extended $\mathrm{H}_{2} \mathrm{~S}$ excursions during January 2010, above the established safe operating limit (SOL) of $6.7 \mathrm{mg} / \mathrm{l}$, as summarised in Table 1.

Table 1 suggests that the $\mathrm{H}_{2} \mathrm{~S}$ excursions were caused by the following factors in combination with cleaning pig runs which tended to magnify the effect.

a. Increased $\mathrm{H}_{2} \mathrm{~S}$ levels in reservoir fluids (in varying proportions from the five entrant pipelines) caused in part by SRB activity from water injection. 


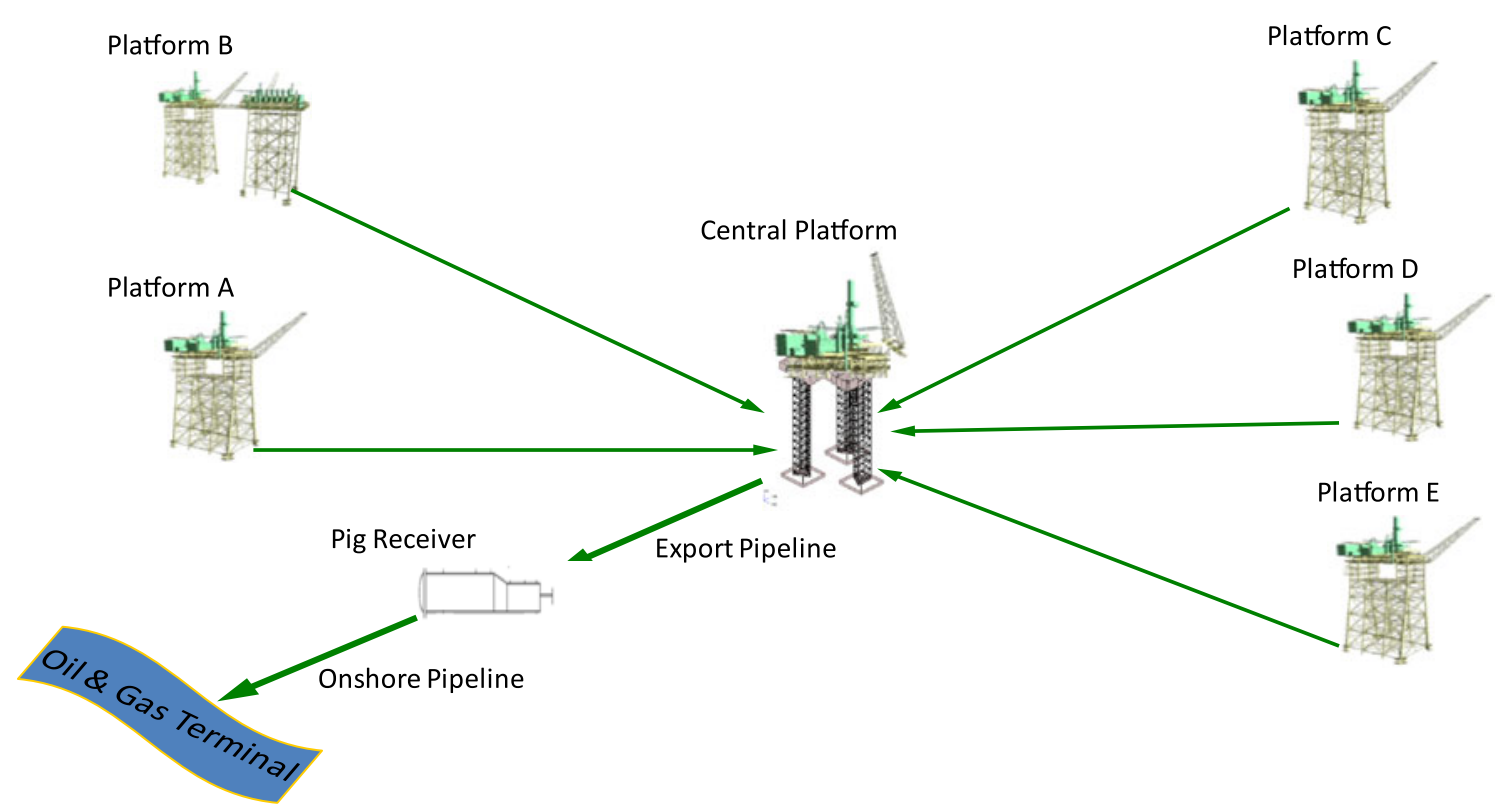

Fig. 1 Schematic of the onshore and offshore pipeline system
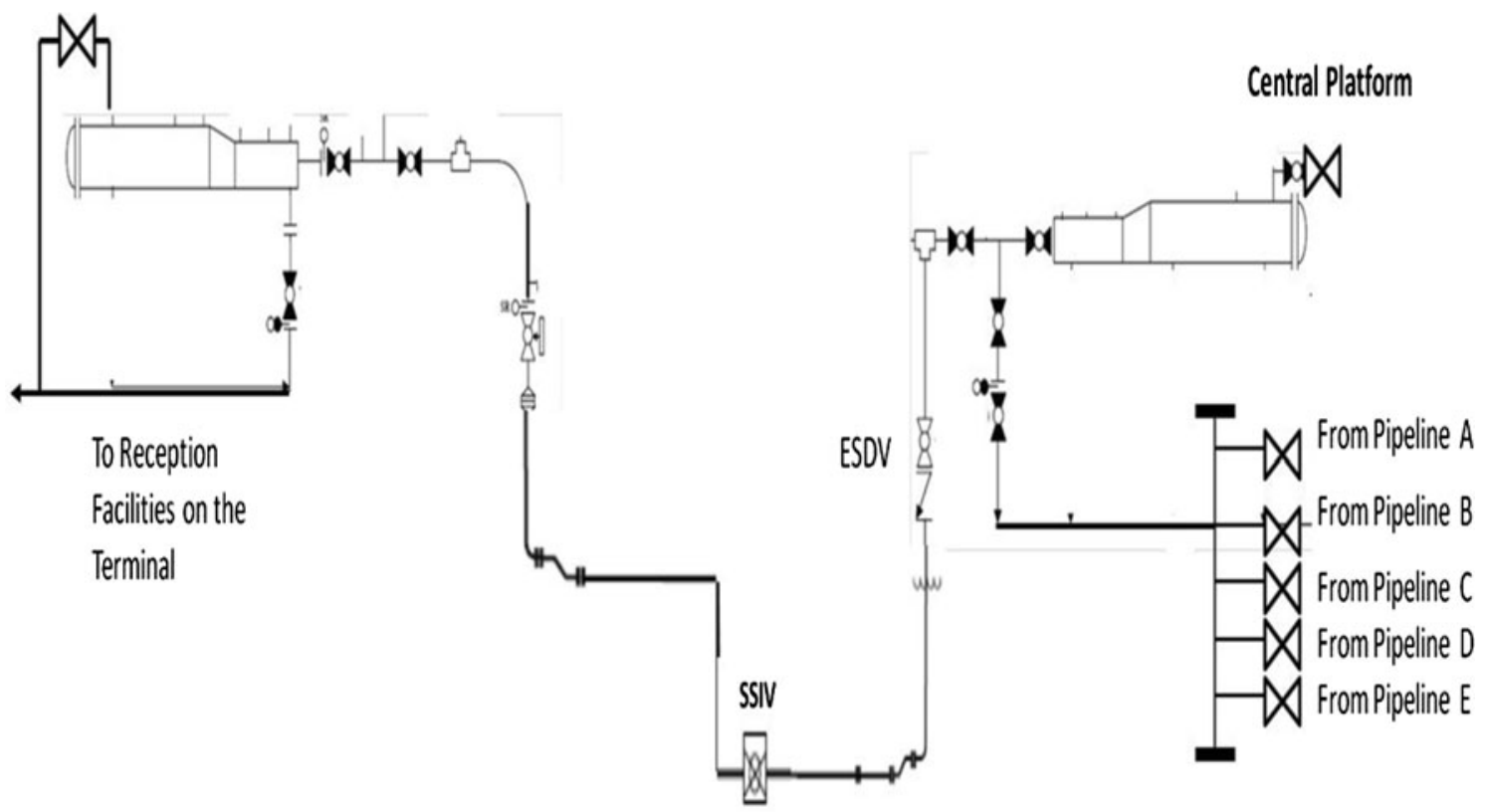

Seabed

Fig. 2 Schematic of the oil export pipeline

b. SRB activity within the pipelines (i.e. export and onshore) and topsides.

c. Gas lift $\mathrm{H}_{2} \mathrm{~S}$ concentrations.

The very high severity of safety, environmental, and business consequences of the failure of these pipelines combined with an equally high probability of catastrophic failure under the current operating regime, represent a very high overall risk scenario. The Pipelines Safety Regulations
(PSR) 1996 [1] requires that "no fluid should be conveyed in a pipeline unless an SOL has been established for it' and also that 'the pipeline should not be operated beyond its safe operating limits'. On the basis of the excursion results and in order to achieve conformity with the PSR, an assessment was performed to determine whether these pipelines were to be considered safe for continued operation. This paper presents the results of this assessment. 
Table 1 Summary of historical $\mathrm{H}_{2} \mathrm{~S}$ and SRB excursions

\begin{tabular}{|c|c|c|c|c|}
\hline \multirow[b]{2}{*}{ Years } & \multicolumn{2}{|c|}{$\mathrm{H}_{2} \mathrm{~S}$ excursions } & \multicolumn{2}{|r|}{ SRB excursions (spike/no spike) } \\
\hline & $\begin{array}{l}\text { Safe operating limit } \\
\quad(\mathrm{SOL}), \mathrm{mg} / \mathrm{l}\end{array}$ & $\begin{array}{l}\text { Range of excursions } \\
\mathrm{mg} / \mathrm{l}\end{array}$ & $\begin{array}{l}\text { Sessile SRB (in pig } \\
\text { wax) }\end{array}$ & Planktonic SRB (in pig water) \\
\hline 2006 & 6.7 & $6.9-8.2$ & No spike & Medium and large spikes \\
\hline 2007 & & $7-8.7$ & No spike & Large and extended spikes \\
\hline 2008 & & $6.9-10.3$ & 1 small spike & Large and extended spikes \\
\hline 2009 & & $6.79-9.26$ & 1 medium spike & Large spikes \\
\hline 2010 & & $6.98-19.6$ & No spike & $\begin{array}{l}\text { Large spikes up to } 03 / 2010 \text {. Thereafter no spikes following } \\
\text { pigging and biociding }\end{array}$ \\
\hline
\end{tabular}

\section{Design and Construction}

The line pipe type is Submerged Arc Welded (SAW) steel pipe API 5L X65. The manufacturers of the pipe from the central platform to landfall were Sumitomo and NKK, Nippon Steel and Kawasaki Steel Corporation. The pipe nominal thickness is $0.75^{\prime \prime}$ (19.05 mm). The manufacturing process is the Nippon steel process which involved quenching and tempering to achieve mechanical properties allowing a carbon equivalent (CE) of 0.34. CE is a measure of weldability which measures the tendency of the weld to form martensite on cooling and to suffer brittle fracture.

The manufacturers of the pipe from landfall to the terminal (i.e. onshore) were Sumitomo and NKK. The pipe nominal thickness is $0.875^{\prime \prime}(22.2 \mathrm{~mm})$. The manufacturing process involved controlled rolling to achieve mechanical properties, allowing a $\mathrm{CE}$ of 0.37 .

A CE value of 0.3 or less is considered safe, while preheat will be required for $\mathrm{CE}$ between 0.4 and 0.6. An approximate value of $\mathrm{CE}$ can be quickly determined from composition using the approximate relation [2]: $\mathrm{CE}=\% \mathrm{C}+\% \mathrm{Mn} / 6+0.05$ or various online calculators.

\section{Mechanism of SSCC and HIC}

\section{Sulphide Stress Corrosion Cracking (SSCC)}

SSCC is caused by hydrogen ions (a by-product of the corrosion process) forming atomic hydrogen atoms which then diffuse into the pipeline steel/weld and embrittle the crystal structure. SSCC then occurs when the tensile stress (pressure surges, residual and external stresses) exceeds the threshold stress. $\mathrm{H}_{2} \mathrm{~S}$ promote diffusion of atomic hydrogen by preventing recombination into the non-diffusable molecular form. The following factors can increase susceptibility to SSCC [3, 4]:

- Gas phase $\mathrm{H}_{2} \mathrm{~S}$ partial pressures above 0.05 psi.

- Steels, welds and weld HAZ with hardness above 275 HV (as per Table 2) or with tensile strength above about $90 \mathrm{ksi}$ (i.e. high strength steels).
Table 2 Maximum hardness limits for oil pipeline

\begin{tabular}{lc}
\hline \multicolumn{1}{c}{ Zone } & $\begin{array}{c}\text { Maximum } \\
\text { hardness } \\
\text { value }\left(\mathrm{HV}_{10}\right)\end{array}$ \\
\hline Parent material & 230 \\
Longitudinal seam weld metal/HAZ & 230 \\
Butt weld metal and HAZ internal (root) traverse & 250 \\
Butt weld metal and external (cap) traverse & 275 \\
Butt weld HAZ internal external (cap) traverse & 275 \\
\hline
\end{tabular}

- $\mathrm{pH}$ less than 4 in the presence of dissolved $\mathrm{H}_{2} \mathrm{~S}$.

- Temperatures in the range ambient to $82{ }^{\circ} \mathrm{C}$ but most severe in the range -6 to $49{ }^{\circ} \mathrm{C}$ due to the favourable diffusion rates of hydrogen.

SSCC can therefore be managed by controlling the above-listed factors (summarised as $\mathrm{pH}, \mathrm{H}_{2} \mathrm{~S}$, temperature and hardness). However, it is obvious that the only options available for the pipelines considered in this paper are reduction of $\mathrm{pH}$ and control of $\mathrm{H}_{2} \mathrm{~S}$ partial pressures below 0.05 psi.

\section{Hydrogen-Induced Cracking (HIC)}

For the export pipeline, HIC can be caused by atomic hydrogen diffusing into the parent plate material or weld usually at sites of inclusions, laminations, corrosion and corrosion products. Therefore plate cleanliness is if paramount importance. Hydrogen sources could be from wet welding (presenting as blisters) and low $\mathrm{pH}$ corrosion. The susceptible temperature range for HIC is between ambient to $150{ }^{\circ} \mathrm{C}$ or higher [3]. HIC favours medium strength steel locations compared with high strength locations such as welds. HIC failures can be initiated without any applied external stress since cracking would be nucleated by the stress field at the tip of the inclusion. Once initiated, crack propagation can be promoted by pressure surges, residual and external stresses. 
Analysed samples of oil pipelines which has been in operation for more than 28 years, were found to have degraded mechanical properties (plasticity and fracture resistance) for up to $2 \mathrm{~mm}$ of the surface depth, caused by repeated and co-joint mechanical loading and hydrogen ingress of oil pipeline metal [5]. This suggests that oil pipelines in end-of-life service (especially for poorly inhibited and high $\mathrm{H}_{2} \mathrm{~S}$ environments) have increased susceptibility to HIC [6].

HIC cracks will nucleate at inclusions near the internal pipeline surface (for example $\mathrm{Si}, \mathrm{Al}$ oxides), corrosion pits (as evidenced by $\mathrm{Fe}_{2} \mathrm{O}_{3}$ and $\mathrm{FeS}$ deposits indicating $\mathrm{H}_{2} \mathrm{~S}$ activity) and weld defects. The initiated cracks will then propagate in a microstructure and texture dependent path, e.g. from HAZ into the pipeline metal. Micro-fractographs have revealed increased branching within the pipe metal.

During testing of X80 steels, HIC was found to occur without any applied external stress and to be associated with high hydrogen diffusivity and trapping density at room temperature. It is specifically sensitive to $\mathrm{Si}$ and $\mathrm{Al}$ oxide inclusions in the microstructure [7]. For X70 pipeline steel, HIC was found to be significantly more sensitive to the oxide inclusions than the nitrides, with crack propagation also being microstructure-sensitive [8]. Very similar results were obtained for HIC behaviour of X100 pipeline steel [9] and the same pattern should be expected for X65 pipeline metal.

HIC-resistance is also highly dependent on crystallographic texture with strong $\langle 111\rangle$ ND fibre textures produced by hot-rolling showing significantly increased HIC-resistance compared to $\langle 001\rangle$ ND and close-to-random textures which are HIC-prone [10].

Traidia et al. [11] developed a finite element model for predicting $\mathrm{HIC}$ in steel pipelines which accounts for hydrogen diffusion, pressure build up, crack extension, $\mathrm{pH}$ and $\mathrm{H}_{2} \mathrm{~S}$ partial pressure. They found that $\mathrm{HIC}$ is reduced when the $\mathrm{pH}$ increases and the partial pressure of $\mathrm{H}_{2} \mathrm{~S}$ decreases.

The required HIC-resistance qualification testing to NACE MR0175/ISO15156 [4] and acceptance criteria and testing methods to NACE TM0284-2003 [12] was not performed for the X65 parent plate and welds. This is considered a significant risk for the operation of this pipeline.

\section{Results}

Historical Corrosion Testing Results

In order to achieve adequate resistance to SSCC, the specifications for the linepipe and bends for the export pipeline including the seam and girth welds should meet the full requirements of ISO 15156 and applicable company standards. This includes restriction on composition and hardness limits (Table 2).

However at the time this pipeline was laid, the maximum hardness requirement of the weld HAZ was $320 \mathrm{HV}$.

\section{Corrosion Testing of Parent Plate material}

Prior to commissioning, samples of the $0.75^{\prime \prime}$ and $0.875^{\prime \prime}$ pipe from NKK and the $0.75^{\prime \prime}$ pipe from Sumitomo were corrosion tested for resistance to SSCC and HIC in accordance with ISO 15156 and using the test methods of NACE TM-02-84 [12]. Results showed a small degree of cracking for the NKK steels and no cracking for the Sumitomo steels.

\section{Corrosion Testing of Parent Plate material}

Prior to commissioning, no samples of the longitudinal seam weld metal/HAZ were corrosion tested for resistance to SSCC and HIC. No butt weld samples (weld metal, root, cap and HAZ) were tested. However, weld qualification tests gave weld root hardness values of 290-297 HV which met the then company acceptance criteria for non-sour service $(<320 \mathrm{HV})$, but exceeded the current ISO 15156 limits for sour service shown in Table 2.

In summary, the entire export pipeline was not originally intended for sour service. On the other hand, the onshore pipeline was originally designed for sour service.

Monitoring/Sampling Results

\section{Throughput}

Three out of five stabilisation trains on the terminal were decommissioned due to significant and progressive reduction in throughput. There has been a simultaneously upward trend in the measured levels of $\mathrm{H}_{2} \mathrm{~S}$. This is likely to be associated with reservoir souring from sea water injection over the life of the field (30 years).

A steady decline in throughput is observed for each entrant pipeline except for pipeline $E$ which has seen a gradual increase since 2006. However from 2006 to date, there was only one $\mathrm{H}_{2} \mathrm{~S}$ excursion recorded for this pipeline. Pipeline $\mathrm{B}$ is identified as the major contributor of $\mathrm{H}_{2} \mathrm{~S}$ to the export pipeline due to the relatively high throughput combined with high $\mathrm{H}_{2} \mathrm{~S}$ contents.

\section{Enumeration of SRB (Sessile and Planktonic)}

Figure 3 shows that from 2006 to 2010 planktonic SRB counts in pig water samples significantly exceeded the threshold (100 MPN/ml). The enumeration method used 
was the serial dilution 'Most Probable Number' technique. It is evident that planktonic SRB activity within the pipelines contributed a significant proportion of the $\mathrm{H}_{2} \mathrm{~S}$ spikes experienced for 13 consecutive days in January 2010, rising to $19.65 \mathrm{mg} / \mathrm{l}$ on 22/01/2010 (Figure 3).

Figure 4 shows a largely flat trend and infrequent excursions of sessile SRB counts in the pig wax, from 2008 to 2010. Microbial corrosion is most likely to have become established at some pipeline locations. This is consistent with 2008 intelligent pigging results indicating the presence of internal corrosion pits.

Historical trends (not shown) also suggest that Tetrakis hydroxymethyl phosphonium sulphate (THPS) contributions/carry over from the entrant pipelines were not effective in controlling the bacterial population in the export and onshore pipelines. This was attributed to incompatibility with several third party entrant inhibitors resulting in significant reduction in efficiency. SRB bacterial colonies in both pipelines were therefore largely uncontrolled for long periods and would most likely have contributed to the extended $\mathrm{H}_{2} \mathrm{~S}$ excursions recently experienced.

\section{$\mathrm{H}_{2} \mathrm{~S}$ and Pigging}

Figure 5 shows an almost linear increase in the average $\mathrm{H}_{2} \mathrm{~S}$ levels from December 2008 to January 2010 when extended excursions were recorded. The historical frequency of contravention of PSR) 1996 above the SOL $(6.7 \mathrm{mg} / \mathrm{l})$ are as follows: 13 times in January 2010 up to $19.64 \mathrm{mg} / \mathrm{l}, 6$ times in February 2010 up to $9.10 \mathrm{mg} / \mathrm{l}$, once in March 2010 and 3 times in July 1020 up to $13.07 \mathrm{mg} / \mathrm{l}$. There were also 5 excursions in total in 2009 up to $9.26 \mathrm{mg} / \mathrm{l}$. The original provision of the corrosion management strategy (CMS) document was to run a clean pig every 10 days. However low flow rates (approximately $0.2 \mathrm{~m} / \mathrm{s}$ ), meant it took the pig 12 days to arrive (i.e. from the central platform to the pig receiver, Figs 1,2). Pigging
Fig. 3 Trend of planktonic SRB in pig water samples

Fig. 4 Trend of sessile SRB in pig wax samples
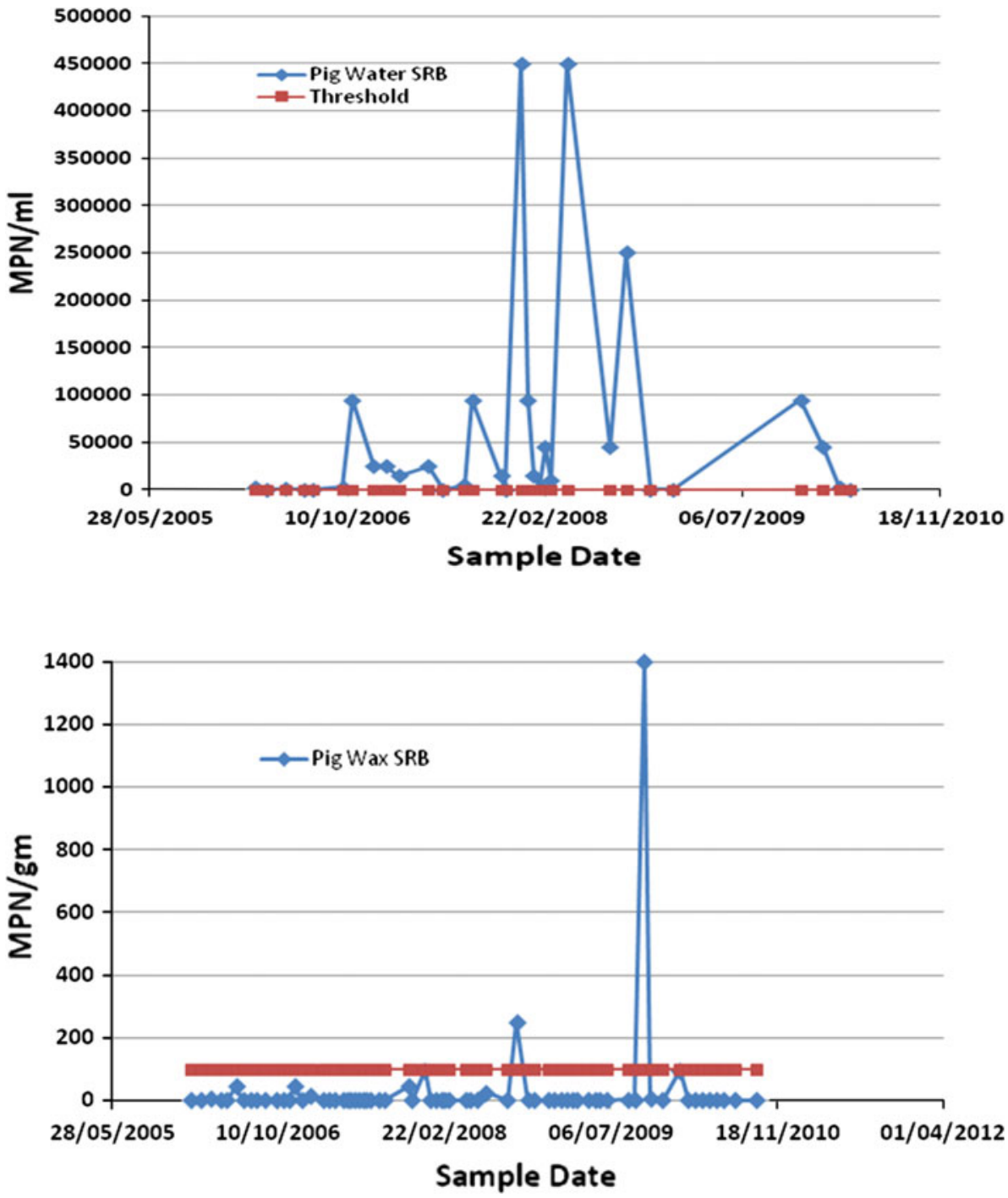
frequency deviations were also not risk assessed and mitigated as recommended. It was, therefore, proposed to mitigate the extended $\mathrm{H}_{2} \mathrm{~S}$ spikes by injecting biocide during the next pigging campaign. This was carried out 1 month after the 2010 excursions with a brush pig launched and followed $48 \mathrm{~h}$ later by $4 \mathrm{~h}$ of biocide injection from the water injection pump. Halfway through, a scrapper pig was then launched. Figure 5 show that this specific intervention successfully reduced $\mathrm{H}_{2} \mathrm{~S}$ levels significantly below the SOL.

The relevant operator of each stream into the export pipeline has been instructed to resume execution of a longstanding recommendation to inject liquid $\mathrm{H}_{2} \mathrm{~S}$ scavenger when $\mathrm{H}_{2} \mathrm{~S}$ levels exceed $4.5 \mathrm{mg} / \mathrm{l}$. This should be continued until the levels fall below this threshold value. This measure would provide a safety net and ensure that the export and onshore pipelines were not operated above the SOL $(6.7 \mathrm{mg} / \mathrm{l})$ in contravention of PSR 1996. Any breach of the SOL will automatically incur an improvement notice and a prohibition order if further breaches are recorded prior to close-out of the initial improvement notice. The terminal operator will not accept the fluids from the entrant pipeline until the prohibition notice is lifted.

\section{$\mathrm{CO}_{2} /$ Corrosivity/pH}

The trend in Fig. 6 shows that the $\mathrm{CO}_{2}$ concentration was largely flat-lined within specification $(0.25$ mass $\%)$ at 0.05 and 0.0 mass \% during 2009 and 2010. This is typical of the trend obtained for all data pre-dating 2008. The absence of any $\mathrm{CO}_{2}$ excursion for both pipelines during this period correlates with results of very low fluid corrosivity for the same period.

Table 3 presents the results of the Ten-Ion analysis of pig water samples taken on 22/06/2010. High acetic acid concentrations (known to increase $\mathrm{CO}_{2}$ corrosion rate) were found to be present in the fluid samples. When the concentration of free acetic acid reaches $57 \mathrm{ppm}$, corrosion rate triples and remains constant until $171 \mathrm{ppm}$ [13]. This can be explained by the ability of the acid to decrease $\mathrm{pH}$, increasing the solubility of $\mathrm{Fe}^{2+}$ and hence reducing the thickness of the carbonate layer.
Fig. 5 Trend of $\mathrm{H}_{2} \mathrm{~S}$ contents (mg/l) vs. threshold $(\mathrm{SOL}=6.7 \mathrm{mg} / \mathrm{l})$

Fig. 6 Historical trend of $\mathrm{CO}_{2}$ concentration
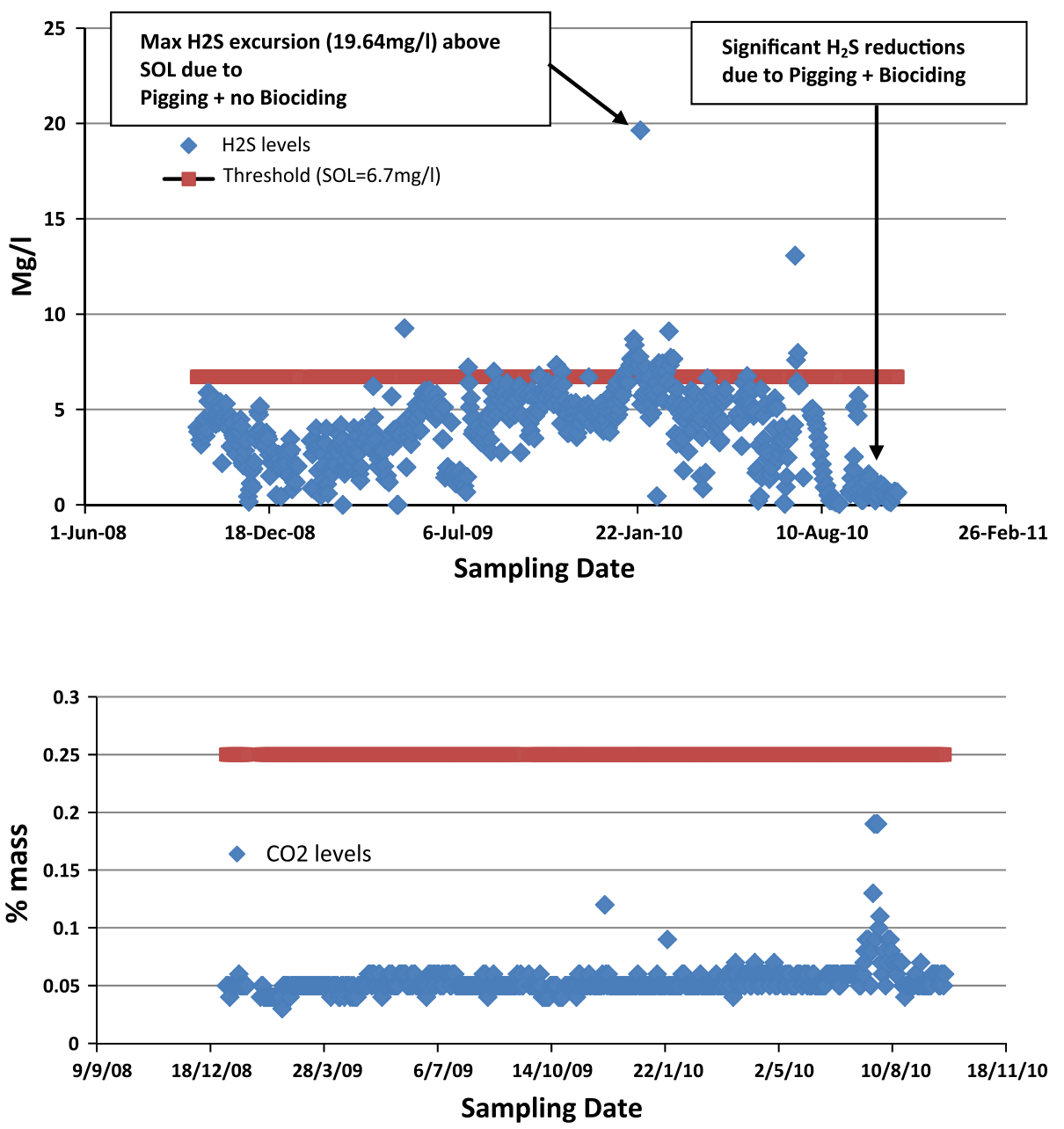
Laboratory results of corrosivities of pig water samples $(0.02 \mathrm{~mm} /$ year, $\quad 0.02 \mathrm{~mm} /$ year and $0.003 \mathrm{~mm} /$ year obtained Sept 2004, Nov 2005 and Aug 2007 respectively) shows that they were well within the design intent of $<0.1 \mathrm{~mm} /$ year. These corrosivity results suggest that the pipeline is adequately protected from $\mathrm{CO}_{2}$ corrosion. However it cannot also be inferred that microbial corrosion or underdeposit corrosion were not occurring.

The low $\mathrm{CO}_{2}$ and corrosivity results are consistent with the near-neutral $\mathrm{pH}$ of 6.7, 7.9 and 7.6 obtained in 2004, $08 / 03 / 10$ and $03 / 04 / 10$, respectively. For purposes of this assessment, it should be noted that there was no historically recorded $\mathrm{pH}$ result that was below 6.5. In summary, the near-neutral $\mathrm{pH}$ levels was the result of low $\mathrm{CO}_{2}$ and high bicarbonate concentrations (e.g. 3638 and $1836 \mathrm{mg} / \mathrm{l}$ in Table 3).

\section{$B S \& W$}

Figure 7 shows that significant water cuts were recorded in January 2010 (40.67, 36.01 and 10.39 mass\%). This correlates with the significant $\mathrm{H}_{2} \mathrm{~S}$ excursions of the same

Table 3 Results of ten-ion analyses of pig water samples

\begin{tabular}{lll}
\hline & Sample $1, \mathrm{mg} / \mathrm{l}$ & Sample 2, mg/l \\
\hline Sodium & 8,179 & 7,988 \\
Calcium & 437 & 337 \\
Strontium & 16.9 & 17.6 \\
Barium & 1.38 & 2.54 \\
Magnesium & 521 & 428 \\
Iron & 4.01 & 6.78 \\
Chloride & 14,087 & 12,886 \\
Sulphate & 1,385 & 1,424 \\
Bicarbonate & 3,638 & 1,836 \\
Acetate & 282 & 908 \\
\hline
\end{tabular}

period. There were only $11 \mathrm{BS} \& \mathrm{~W}$ excursions (up to 31.27 mass\%) during 2008 and 2009 otherwise most of the sampled results were within specification. The trend suggests that since the low number of $\mathrm{BS} \& \mathrm{~W}$ excursions correlated with low $\mathrm{H}_{2} \mathrm{~S}$ levels, a relatively lower risk of SSCC is indicated. Therefore $\mathrm{H}_{2} \mathrm{~S}$ levels in the water cut and consequently the risk of SSCC can be significantly reduced by maintaining BS\&W levels below the 5 mass $\%$ threshold.

\section{Corrosion Inhibitor}

Corrosion inhibitor (CI) levels of the co-mingled fluids (in the export and onshore pipelines) were never analysed due to suspect accuracy of the blend of different CI types. However high CI concentrations have been historically recorded for each of the entrant pipelines in addition to the low corrosivity results presented in " $\mathrm{CO}_{2} / \mathrm{Corrosivity/pH"}$ section. This suggests that both pipelines receive adequate corrosion protection. Microbial and pitting corrosion at underdeposit locations could not be ruled out given the possibility of biocide and inhibitor shielding, respectively.

\section{Discussions}

\section{Assessment of SSCC Risk}

According to NACE ISO 15156, X65 is not at risk of SSCC when operating in the SCC Region 0. The environmental limits are shown in Fig. 8 to be between 2.5 and 6.5 for $\mathrm{pH}$ and up to $0.3 \mathrm{kPa}(0.05 \mathrm{psi})$ for $\mathrm{H}_{2} \mathrm{~S}$ partial pressure.

Results presented in " $\mathrm{CO}_{2} /$ Corrosivity/pH" section showed that the recorded $\mathrm{pH}$ were 7.8 and 7.9 during 2009 and 2010, respectively, and historically never dropped below 6.7. It is evident from Fig. 8 that $\mathrm{pH}$ would have to be less than 6.5 for the pipeline material (X65) to move into any of the SCC regions of environmental severity ( 0 ,
Fig. 7 Historical trend of BS\&W

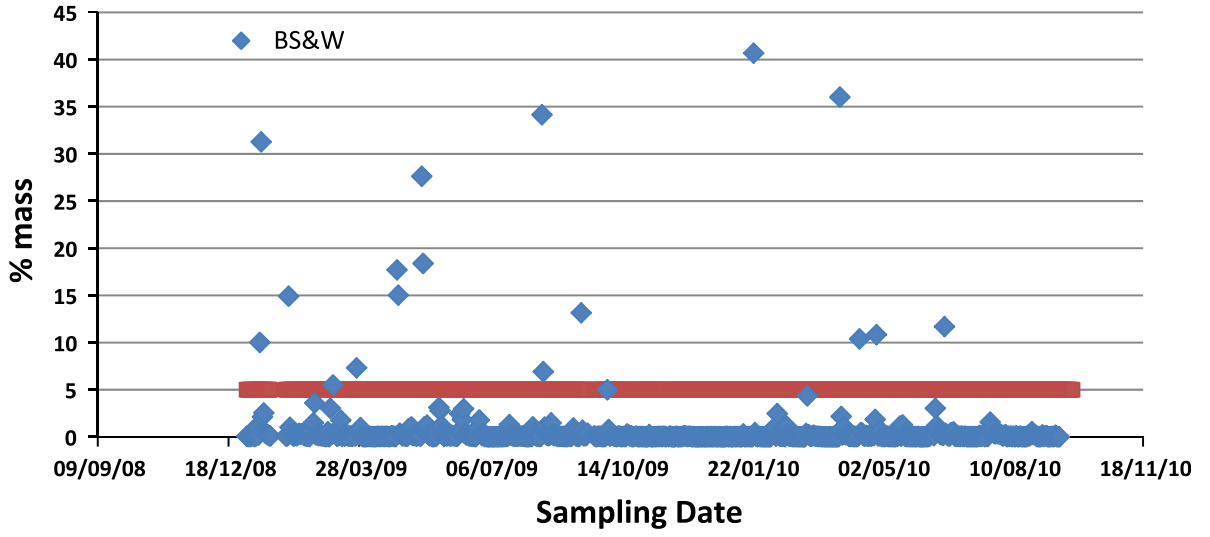


Fig. 8 SCC regions of environmental severity

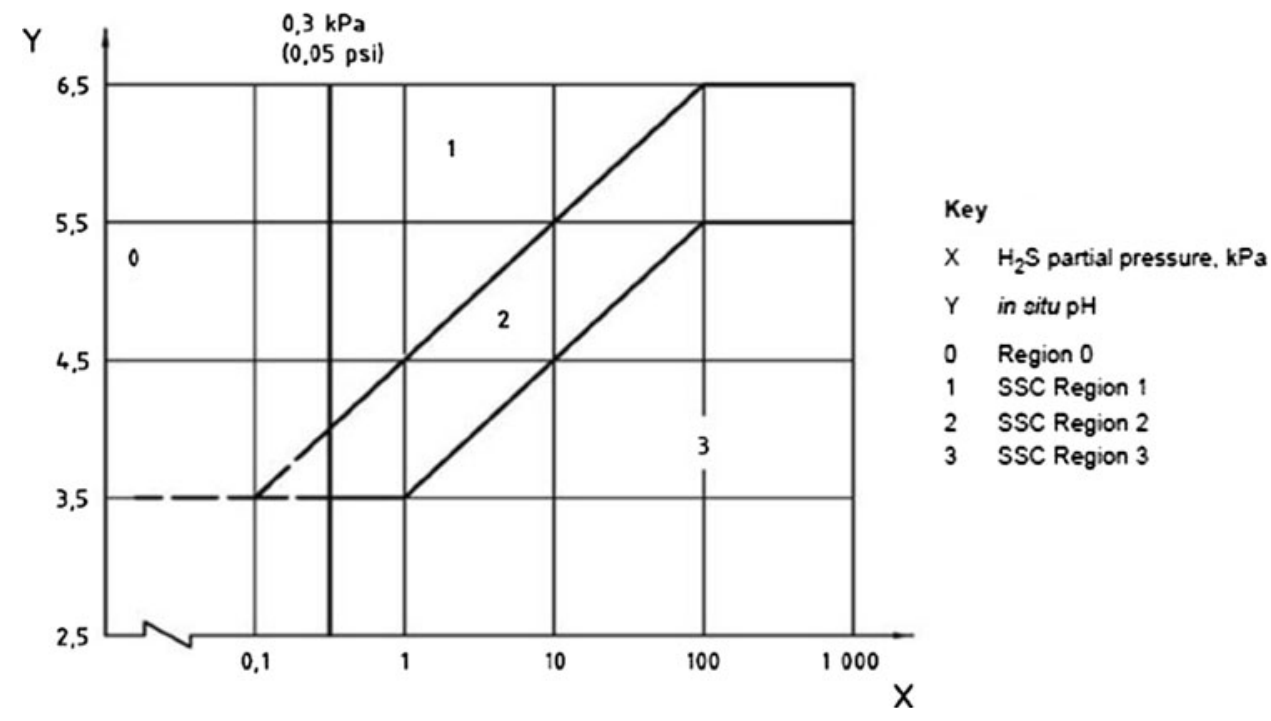

1, 2 and 3). On the basis of these recorded $\mathrm{pH}$ results, it will be safe to conclude that the $2010 \mathrm{H}_{2} \mathrm{~S}$ excursions (up to $19.64 \mathrm{mg} / \mathrm{l}$ ) did not represent a SSCC risk for both pipelines. Sampling and analysis of pig water $\mathrm{pH}$ is, however, strongly recommended for every pig receipt in order to monitor when the $\mathrm{pH}$ falls below 6.5 and hence constitute an operational SSCC risk. Whenever $\mathrm{H}_{2} \mathrm{~S}$ excursions occur, the $\mathrm{pH}$ values obtained should be used to determine the SCC region of environmental severity and assess if there is an enhanced and continuing risk of SSCC. Increased $\mathrm{CO}_{2}$ levels would potentially reduce $\mathrm{pH}$ hence off-spec $\mathrm{CO}_{2}$ concentrations will be an important trigger for $\mathrm{pH}$ sampling and analysis. It is important to note that when off-spec $\mathrm{CO}_{2}$ levels combine with high levels of acetic acid (currently seen in the fluids), steep reductions of $\mathrm{pH}$ below 6.5 could potentially occur and consequently move the SSC risk into an undesirable region of SCC severity.

The SOL for both pipelines was calculated as $6.7 \mathrm{mg} / \mathrm{l}$ in 2005 using the HYSYS simulation [14]. This value corresponds to the ISO 15156 requirement that the $\mathrm{H}_{2} \mathrm{~S}$ partial pressure should be less than $0.3 \mathrm{kPa}(0.05 \mathrm{psi})$ in order to achieve resistance to SSCC. In other words, the line pipe material will not be considered to be at risk of SSCC when the $\mathrm{H}_{2} \mathrm{~S}$ partial pressure is below this value. Given that the determined SOL value of $6.7 \mathrm{mg} / \mathrm{l}$ correspond to $\mathrm{H}_{2} \mathrm{~S}$ partial pressure of $0.05 \mathrm{psi}$, it can be deduced from Fig. 8 that the maximum $\mathrm{H}_{2} \mathrm{~S}$ excursion $(19.64 \mathrm{mg} / \mathrm{l})$ experienced on 24 January 2010 would move the pipeline into the more severe SSC Region 1, if $\mathrm{pH}$ fell to less than 6.5. Under environmental conditions of $\mathrm{pH}$ and $\mathrm{H}_{2} \mathrm{~S}$ partial pressure, the risk of SSCC would increase and pipelines operating in this region will require selection of materials and weldments which are more stringent than for Region 0 . However, the $\mathrm{pH}$ and maximum $\mathrm{H}_{2} \mathrm{~S}$ spike levels during the extended excursions did not align with any of the SSCC regions of risk severity. Both the export and onshore pipelines are not considered to be at risk of SSCC and are consequently considered safe for continued operations.

In order to provide resistance to SSCC, NACE ISO 15156 also requires compliance with the hardness limits for the parent metal, weld root and weld cap for pipeline operation in SCC Region 0. The welding procedure qualification tests for the X65 pipeline material recorded a weld root hardness of $275 \mathrm{HV}_{10}$ conformed to the then company standards $\left(<320 \mathrm{HV}_{10}\right) 30$ years ago but exceeds the current NACE ISO 15156 requirements $\left(\leq 250 \mathrm{HV}_{10}\right)$. The weld qualification hardness data for the other test locations shown in Table 2, were not provided. It is likely that there are localised weldment hard-spots which will represent an ongoing operational risk for both pipelines.

In the event that the export and onshore pipelines operate in SCC Region 1 (given the levels of excursion of $\mathrm{pH}$ and $\mathrm{H}_{2} \mathrm{~S}$ partial pressure) ISO 15156-2 Annexe A, Section A.4.3 [4] states that for service in the Region 1 environment, "yield strengths of up to $550 \mathrm{MPa}(80 \mathrm{ksi})$ have proven acceptable. Typically fabrication and field weld hardness should not exceed $300 \mathrm{HV}$ ". On this basis, the weld root hardness of $275 \mathrm{HV}_{10}$ for the export pipeline is considered to conform to the specified hardness limit for Region 1. For the onshore pipeline, no PWHT was performed for the welded-on chemical injection valves which fail to meet ISO 15156-2 requirements that 'the hardness of carbon and alloy steels shall not exceed $22 \mathrm{HRc}$ and should be used in one of four heat-treatable conditions' (ref). In view of the risk presented by this 
non-conformity, it is recommended that RBI frequencies should be reviewed and possibly increased if $\mathrm{pH}$ and $\mathrm{H}_{2} \mathrm{~S}$ partial pressures move the SCC region of severity from 0 to 1 . It is also recommended to develop an inspection plan that will ensure that the critical weld locations (100\% for the export pipeline and all chemical injection welds for the onshore pipeline) receive adequate inspection coverage.

Based on the results and the specific recommendations in this section, the export and onshore pipelines were considered to be safe for continued operation.

\section{Assessment of HIC Risk}

Since initial HIC testing of the parent plate and welds were not performed, it is likely that the risk of HIC would have further increased on account of the pipeline being operated for 30 years and being subject to degraded mechanical properties within $2 \mathrm{~mm}$ depth of the pipeline internal surface. Adequate corrosion inhibition and pigging is recommended in order to ensure that the pipeline is essentially free of corrosion and corrosion products which would increase the risk of HIC. Existing defect locations identified during the 2008 ILI should be investigated and inspected for possible initiation and crack propagation.

HIC is reduced when $\mathrm{pH}$ increases and the partial pressure of $\mathrm{H}_{2} \mathrm{~S}$ decreases. Therefore, it is recommended that $\mathrm{pH}$ should be maintained at near-neutral levels (above 6.5), while reducing $\mathrm{H}_{2} \mathrm{~S}$ levels to very low levels by continued implementation of current planned pigging and biociding which has significantly reduced $\mathrm{H}_{2} \mathrm{~S}$ levels to less than $2 \mathrm{mg} / \mathrm{l}$ (August 2010).

\section{General Conclusions and Recommendations}

The operational risks of these pipelines and which potentially increases susceptibility to SSCC and HIC are:

- $\mathrm{H}_{2} \mathrm{~S}$ excursions above the SOL and up to $19.64 \mathrm{mg} / \mathrm{l}$.

- No butt weld samples originally tested for SSCCresistance.

- Weld qualification (hardness) test results exceeding ISO 15156 limits for sour service.

- Export pipeline not designed for sour service.

- Onshore pipeline except the chemical injection welds are designed for sour service.

- Pipeline is in end-of-life duty and, therefore, more susceptible to HIC damage.

The following measures were recommended for maintaining $\mathrm{H}_{2} \mathrm{~S}$ levels below the $\mathrm{SOL}$ and hence minimising the risk of SSCC.
- $\mathrm{H}_{2} \mathrm{~S}$ scavenging by all entrant pipelines until $\mathrm{H}_{2} \mathrm{~S}$ levels are reduced to less than $4.5 \mathrm{ppm}$. Contravention will incur an improvement notice. Further contravention prior to discharge of the improvement notice will attract a prohibition notice.

- Implementation of specified pigging frequencies (every 12 days) accompanied by biocide injection.

- BS\&W levels should be maintained below the specification threshold of less than 5 mass\%.

Results of sampling analysis found that $\mathrm{pH}$ levels have been historically near-neutral (above 6.5) and corrosivities were also low corresponding to adequate corrosion inhibition.

The risk of SSCC was found to be low given that historical $\mathrm{pH}$ and $\mathrm{H}_{2} \mathrm{~S}$ results did not align with any of the SSCC regions of environmental severity $(0,1,2,3) . \mathrm{pH}$ testing should be undertaken during every pig receipt (especially during $\mathrm{H}_{2} \mathrm{~S}$ excursions) and an assessment subsequently performed to determine whether the pipeline operates in undesirable SSCC regions of severity 1, 2, or 3. The high risk of $\mathrm{HIC}$ is minimised by maintaining $\mathrm{pH}$ at near-neutral and $\mathrm{H}_{2} \mathrm{~S}$ very low using the mitigation methods recommended above.

On the basis of the $\mathrm{pH}$ results and as long as $\mathrm{pH}$ remains above 6.5 , both pipelines have been considered safe for continued operation.

Open Access This article is distributed under the terms of the Creative Commons Attribution License which permits any use, distribution, and reproduction in any medium, provided the original author(s) and the source are credited.

\section{References}

1. The Pipelines Safety Regulations 1996. http://www.legislation. gov.uk/

2. International Institute of Welding (IIW). Technical Report. IIW Doc IX 535-67 (1967)

3. API 571, First Edition, December 2003

4. NACE MR0175/ISO15156-2, Part 2: Cracking-Resistant Carbon and Low Alloy Steels, and the Use of Cast Irons

5. Kryzhanivs'kyi, E.I., Nykyforchyn, H.M.: Specific features of hydrogen-induced corrosion degradation of steels of gas and oil pipelines and oil storage reservoirs. Mater. Sci. 47(2), 127-136 (2011)

6. Radkevych, O.I., Chumalo, H.V.: Damage to the Metal of Industrial Pipelines in a Hydrogen Sulfide Environment. Mater. Sci. 39(4), 596-600 (2003)

7. Xue, H.B., Cheng, Y.F.: Characterization of inclusions of X80 pipeline steel and its correlation with hydrogen-induced cracking. Corros. Sci. 53(4), 1201-1208 (2011)

8. Dong, C.F., Li, X.G., Liu, Z.Y., Zhang, Y.R.: Hydrogen-induced cracking and healing behaviour of X70 steel. J. Alloys Compds. 484(1-2), 966-972 (2009)

9. Dong, C.F., Liu, Z.Y., Li, X.G., Cheng, Y.F.: Effects of hydrogen-charging on the susceptibility of X100 pipeline steel to hydrogen-induced cracking. Int. J. Hydrogen Energy 34(24), 9879-9884 (2009) 
10. Venegas, V., Caleyo, F., Baudin, T., Espina-Hernández, J.H., Hallen, J.M.: Study of hydrogen-induced cracking in API-5LX46 pipeline steel. Corros. Sci. 53(12), 4204-4212 (2011)

11. Traidia, A., Alfano, M., Lubineau, G., Duval, S., Sherik, A.: An effective finite element model for the prediction of hydrogen induced cracking in steel pipelines. Int. J. Hydrogen Energy 37(21), 16214-16230 (2012)
12. ANSI/NACE TM0284-2011: Evaluation of Pipeline and Pressure Vessel Steels for Resistance to Hydrogen-Induced Cracking

13. Singer, M., Nesic, S., Gunaltun, Y.: Top of the line corrosion in the presence of acetic acid and carbon dioxide. Paper no. 04377 presented at CORROSION 2005

14. HYSYS 2004.2: Simulation Basis. Aspen Technology, Inc., Ten Canal Park, Cambridge, MA. http://www.aspentech.com 